\title{
PERCEPÇÕES DE PROFESSORES DOS ANOS INICIAIS DO ENSINO FUNDAMENTAL EM RELAÇÃO AO ENSINO DE ESTATÍSTICA
}

\author{
PERCEPTIONS OF TEACHERS IN THE EARLY YEARS OF \\ ELEMENTARY SCHOOL TOWARDS TEACHING STATISTICS
}

\author{
PERCEPCIONES DE PROFESORES DE LOS AÑOS \\ INICIALES DE LA ENSEÑANZA FUNDAMENTAL EN \\ RELACIÓN CON LA ENSEÑANZA DE ESTADÍSTICA
}

\author{
Ailton Paulo de Oliveira Júnior \\ Professor Doutor da Universidade Federal do ABC (UFABC). \\ Santo André - SP, Brasil. \\ ailton.junior@ufabc.edu.br \\ Márcia Lopes Vieira \\ Mestrado em Educação pela Universidade Federal do Triângulo Mineiro - UFTM. \\ Pedagoga do Instituto Federal do Triângulo Mineiro (IFTM). \\ Uberlândia-MG, Brasil. \\ marcialopes@iftm.edu.br
}

\begin{abstract}
Resumo: Investigar as percepções de professores de Matemática é considerar que na escola, as atividades educativas, que diferem daquelas que ocorrem em outros contextos, são determinadamente sistemáticas e apresentam uma intencionalidade deliberada e compromisso explícito em dar acesso ao conhecimento formalmente organizado. Portanto, o objetivo deste trabalho foi investigar as percepções de 55 professores dos anos iniciais do Ensino Fundamental, em oito escolas públicas e privadas da cidade de Uberlândia (MG), no tocante ao Ensino de Estatística. Assim, pretendeu-se investigar as percepções deste grupo de professores a partir das seguintes questões: (1) $O$ que é Estatística para você? (2) Em sua opinião como uma pessoa adquire conhecimento em Estatística? (3) Como você trabalha os conteúdos estatísticos em suas aulas? (4) Como você incorpora situações do cotidiano em suas aulas de Estatística? Pela análise de conteúdo de Bardin verificou-se que os professores consideram a Estatística como conjunto de técnicas e métodos de pesquisa que entre outros tópicos envolve a coleta dos dados, o processamento e a análise das informações; ensinam os conteúdos estatísticos por meio de técnicas de ensino que relacionam os conteúdos estatísticos com os dados utilizados no cotidiano do aluno; e parecem acreditar que o conhecimento deve ser construído pelos estudantes à medida que as atividades didáticas fazem uso de significados lógicos, de ideias relevantes, como também, de ideias que já se encontram disponíveis na estrutura cognitiva deste.
\end{abstract}

Palavras-chave: Percepções. Professores. Ensino Fundamental. Ensino de Estatística.

\begin{abstract}
Investigate the perceptions of Teachers of Mathematics is to consider that in schools, educational activities, which differ from those that occur in other contexts, are determinedly systematic and feature a deliberate intention and explicit commitment in giving access to knowledge formally organized. Therefore, the objective of this study was to investigate the perceptions of 55 teachers in the early years of elementary education, in eight public and private schools in the city of Uberlândia (MG), towards the teaching of Statistics. Thus, we sought to investigate the perceptions of this group of teachers from the following issues: (1) What does 'statistics' mean to you? (2) How does a person get knowledge in statistics? (3) How do you work on statistical topics with your students? (4) What do you think about the use of memorization as a tool in teaching and learning statistics? By Bardin's content analysis it was found that teachers consider the statistics as a set of techniques and methods of research that among other topics involves the collection of data, the processing and analysis of information; teach the statistical content by means of teaching techniques that relate the content with the statistical data used in the everyday life of the student; and seem to believe that knowledge should be built by the students to the extent that the didactic activities make use of logical meanings of relevant ideas, as well as ideas that are already available in the cognitive structure of this.
\end{abstract}

Keywords: Perceptions. Teachers. Elementary School. Teaching Statistics.

Resumen: Investigar las percepciones de los profesores de matemáticas es considerar que en las escuelas, actividades educativas, que difieren de las que ocurren en otros contextos, son decididamente una característica sistemática y deliberada intención y compromiso explícito en dar acceso al conocimiento formalmente organizados. Por lo tanto, el objetivo de este estudio fue investigar las percepciones de 55 profesores en los primeros años de educación primaria 
en ocho colegios públicos y privados en la ciudad de Uberlândia (MG), en relación con la enseñanza de la estadística. Se pretende investigar las percepciones de este grupo de profesores de los siguientes temas: (1) ¿Qué és 'Estadística' para usted? (2) ¿Cómo puede una persona obtener conocimientos en estadísticas? (3) ¿Cómo puede trabajar en temas estadísticos con sus alumnos? (4) ¿Qué opinas sobre el uso de la memorización como una herramienta de enseñanza y aprendizaje estadísticas? Por Bardin el análisis de contenido se constató que los maestros consideran la estadística como un conjunto de técnicas y métodos de investigación que, entre otros temas, implica la recogida de datos, el procesamiento y análisis de información; enseñar el contenido estadístico por medio de técnicas de enseñanza que relacionar el contenido con los datos estadísticos que se utilizan diariamente en alumno; y parece que creen que el conocimiento debe ser construido por los estudiantes en la medida en que las actividades didácticas hacen uso de significados lógicos de ideas pertinentes, así como las ideas que ya están disponibles en la estructura cognitiva de esta.

Palabras clave: Percepciones. Profesores. Educación primaria. Enseñanza de la Estadística.

\section{INTRODUÇÃO}

A sociedade atual exige atitude crítica dos cidadãos, no que se refere a reconhecer e a tratar os problemas surgidos, a fim de que as possíveis respostas sejam apresentadas da forma mais adequada possível.

Consideramos que a escola é o melhor ambiente para promover tais discussões, já que é, no seu espaço, onde ocorrem os processos formais de ensinar e aprender. É preciso que tais processos sejam discutidos e aprimorados.

Além destes aspectos, no mundo atual, com a presença constante da Estatística na vida dos cidadãos, tornou-se necessário ensinar esta disciplina a um número crescente de pessoas, sobretudo para as crianças.

E a percepção que o professor tem sobre a Estatística e seu ensino é de especial interesse para a implementação bem-sucedida dos programas de matemática da Educação Básica. Por esse motivo, neste trabalho, pretendemos determinar essa percepção em um grupo de professores dos anos iniciais do Ensino Fundamental em exercício.

Considerando-se ainda que, no Ensino da Estatística, é fundamental que se investigue a prática pedagógica do professor de forma a conceber os caminhos trilhados em sua formação e a forma com que este professor faz a sua prática, estabelecemos a seguinte questão de pesquisa: Quais as percepções de professores que ensinam matemática nos anos iniciais do Ensino Fundamental em relação ao Ensino de Estatística?

Portanto, a partir da publicação dos Parâmetros Curriculares Nacionais - PCN - Matemática dos anos iniciais do Ensino Fundamental, Brasil (1997), a Estatística passou a ser foco de trabalho de muitos educadores e foi inserida em livros didáticos deste nível de escolaridade, pois um dos seus princípios norteadores reconhece a importância das diferentes formas de perceber as informações matemáticas e a sua relação significativa com a realidade do educando. Ensinar Estatística para crianças tornou-se uma necessidade social com vistas a desenvolver no aluno a habilidade de coletar, organizar, interpretar e tomar decisões frente aos dados.

Além dos PCN, observamos na nova Base Nacional Comum Curricular - BNCC, Brasil (2017, p. 10), que elementos da incerteza e do tratamento de dados devem ser estudados na também nova unidade temática "Probabilidade e Estatística".

Para Farias, Soares e César (2003), a Estatística é uma ciência que se dedica ao desenvolvimento e ao uso de métodos para a coleta, organização, apresentação e análise de dados. Conforme a sua relevância na vida dos cidadãos entende-se que a Estatística deve fazer parte do currículo de Matemática desde os primeiros anos de escolarização.

Costa e Nacarato (2011) demonstram que o conteúdo de Estatística no Brasil além de ter sido inserido tardiamente nos currículos oficiais para a disciplina de Matemática da Educação Básica, se comparado a outros países, esta inserção aconteceu sem que houvesse uma formação prévia dos professores para trabalhar tal conteúdo.

Guimarães et al. (2009) também esclarecem que, por ser recente a introdução da Estatística nos PCN, muitos professores não tiveram uma formação sistematizada a respeito da Educação Estatística e, assim, não reconhecem a importância da inclusão desse conteúdo em sua prática docente. 
Na visão de Batanero (2001), Estrada, Bazán e Aparicio (2010), Estrada e Batanero (2008), Lopes (2008; 2010) e Lopes et al. (2010), os saberes estatísticos tornam-se ferramentas essenciais para a tomada de decisão no mundo contemporâneo. Neste sentido, na medida em que tais saberes passam a integrar os currículos escolares desde ao início da escolarização, principalmente no que tange às questões econômicas e sociais, ganha força a necessidade de que o professor compreenda e utilize adequadamente conhecimentos estatísticos contextualizados.

De acordo com Mendes (2003), é necessário que os professores promovam a alfabetização estatística no contexto escolar, partindo do pressuposto que é possível ensinar os alunos a coletar dados e construir gráficos já nos anos iniciais.

E, portanto, o processo de ensinar e aprender é complexo, e é influenciado por aquilo que se conhece e por aquilo que se acredita. Está intimamente ligado ao relacionamento entre alunos e professores e apresenta melhor resultado quando há uma correspondência entre objetivos e valores a serem atingidos.

Esses resultados, por sua vez, também estão relacionados à prática docente dos professores e às estratégias de ensino adotadas em sala de aula. E não basta o professor conhecer os conteúdos específicos de sua disciplina, é necessário saber articular esses conhecimentos a situações concretas de ensino.

Assim, investigar as percepções de professores de Matemática é considerar que na escola, as atividades educativas, que diferem daquelas que ocorrem em outros contextos, são determinadamente sistemáticas e apresentam uma intencionalidade deliberada e compromisso explícito em dar acesso ao conhecimento formalmente organizado.

Houaiss e Villar (2001, p. 2183), entre outras acepções, definem percepção como: "ato ou efeito de perceber". Já para a palavra perceber, os autores atribuem o significado de: "formar ideias a respeito de; compreender".

E entende-se como percepção a elaboração mental das sensações. A percepção delimita tudo aquilo que somos capazes de sentir e compreender, correspondendo, assim, a uma ordenação seletiva dos estímulos, criando uma dicotomia entre o que percebemos e o que não percebemos (OSTROWER, 1993). Ademais,

para tanto, a percepção consciente na ação humana se nos afigura com uma premissa básica da criação, pois além de resolver situações imediatas o homem é capaz de a elas se antecipar mentalmente. Não antevê apenas certas soluções. Mais significativa ainda é a sua capacidade de antever certos problemas (OSTROWER, 1993, p. 2).

A partir das definições do que seja percepção, Ferreiro (2011) destaca a importância de conhecer como os professores percebem o processo ensino aprendizagem em que estão inseridos. Ela alega que nenhuma prática pedagógica é neutra. Todas estão apoiadas em certo modo em conceber o processo de aprendizagem e o objeto dessa aprendizagem. São provavelmente essas práticas (mais do que os métodos em si) que têm efeitos mais perduráveis em longo prazo, ou seja, não é possível ensinar nada sem partir de uma ideia de como ocorre a aprendizagem.

Assim, focando nos professores de Matemática dos anos iniciais, Cury (1999) destaca que estes concebem a Matemática a partir das experiências que tiveram como alunos e com antigos professores, do conhecimento que construíram, das opiniões de seus professores, enfim, das influências socioculturais que sofreram durante suas vidas, influências que vêm sendo construídas, passadas de geração para geração.

Segundo Soares (2011) é necessário voltar o olhar para professores no que se refere à formação para ensinar Matemática e Estatística aos alunos dos anos iniciais do Ensino Fundamental. E ainda segundo Lemos e Ferreira (2006), a estatística deve ser trabalhada de maneira efetiva nos anos iniciais, envolvendo o ensino de interpretação e construção de gráficos e tabelas.

Colodel e Brandalise (2010) realizaram uma investigação com o objetivo de diagnosticar as percepções dos professores dos anos iniciais do Ensino Fundamental ( $1^{\circ}$ ao $5^{\circ}$ ano) de uma rede municipal de ensino sobre as concepções de ensino e aprendizagem relativas ao conhecimento estatístico que desenvolvem em suas práticas pedagógicas. Utilizou-se a metodologia do discurso do sujeito coletivo - DSC para analisar os depoimentos dos 67 docentes participantes. Os resultados revelaram que os conteúdos matemáticos referentes ao bloco Tratamento da Informação estão 
presentes nas práticas pedagógicas da maioria dos professores, porém eles apontam a necessidade de assistência em relação ao Tratamento da Informação para o bom desenvolvimento de habilidades e competências matemáticas com os alunos.

Costa e Poloni (2012), em pesquisa com 64 cursos de Pedagogia no estado de São Paulo sobre a percepção de concluintes de Pedagogia em relação à sua formação para a docência de Matemática, quando perguntados sobre quais conteúdos matemáticos dos anos iniciais do Ensino Fundamental se sentem mais ou menos preparados para ensinar, os elementos do Tratamento da Informação, especificamente as noções de Estatística, mostraram-se como conteúdo em que se sentem menos preparados.

E Santos, Ortigão e Aguiar (2014), ao investigarem os possíveis temas matemáticos mais valorizados por professores dos anos iniciais de Pernambuco, constataram uma maior abordagem do bloco Números e Operações, em detrimento dos demais, como Grandezas e Medidas, Tratamento da Informação (Estatística, Probabilidade e Análise Combinatória), etc. Para os autores, há uma atenção maior dos professores com atividades mais próximas daqueles presentes nos roteiros dos livros didáticos, em detrimento de atividades que "[...] envolvem habilidades mais complexas (resolver e elaborar problemas, compreender, relacionar, discutir, etc.) [...]" (SANTOS; ORTIGÃO; AGUIAR, 2014, p. 659).

Oliveira Júnior et al. (2013) investigaram as percepções em relação ao ensino de Estatística de 40 professores que atuam nos anos iniciais de escolas públicas e privadas, no município de Uberaba, Minas Gerais. Foi constatada que para a maioria dos professores a estatística é uma ciência exata, que lida com números, gráficos e tabelas, auxilia na interpretação das informações do dia a dia e é importante no cotidiano. Também concordam que é uma disciplina difícil de ser trabalhada por não terem uma sequência didática que favoreça o ensino. O estudo mostra ainda a necessidade de se qualificar os professores dos anos iniciais para terem um melhor conhecimento estatístico e que lhes permita compreender seu papel no processo de construção desse conhecimento na Educação Básica.

Ainda destacamos o trabalho de Bessa e Leite (2015) que estudaram as percepções e significado que 43 professores da Educação Infantil e dos anos iniciais do Ensino Fundamental atribuem à disciplina de matemática e como essas interferem nos processos de ensino aprendizagem e na prática pedagógica dessa disciplina. Dentre os resultados apresentados, os professores reconhecem o valor e a importância da matemática para a vida, mas não têm uma explicação clara para isso. A prática pedagógica preferida pelos professores é a transmissão do conhecimento, embora admitam a necessidade de um ambiente solicitador e lúdico.

Consideramos que o estudo das percepções dos professores seja uma tarefa de extrema relevância, na medida em que colabora para a compreensão acerca da constituição da identidade profissional, contribuindo assim para qualificar a formação de professores. Ao longo de sua carreira acadêmica e profissional, o professor vai construindo saberes e o referencial que fundamenta assuas ações por meio daquilo que percebe, interpreta e atribui significado a sua atividade, em um constante processo crítico-reflexivo sobre a sua própria prática.

\section{PROCEDIMENTOS METODOLÓGICOS}

Tendo em vista o tema e o problema de pesquisa levantado, o objetivo deste trabalho foi pesquisar as percepções de professores dos anos iniciais do Ensino Fundamental em relação ao ensino de Estatística em oito escolas da cidade de Uberlândia (MG), sendo uma da rede Federal, duas da Estadual, duas da Municipal e três da rede Privada de Ensino. A Figura 1 exibe a estrutura do problema de pesquisa.

Figura 1 - Estrutura do problema de pesquisa.

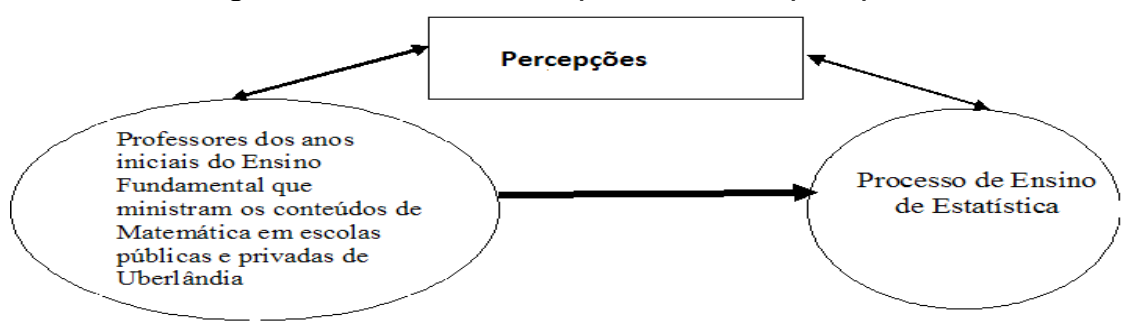


Fonte: Elaborado pelos autores.

Os participantes dessa pesquisa são 55 (cinquenta e cinco) professores dos anos iniciais do Ensino Fundamental de escolas de Uberlândia, Minas Gerais que lecionam conteúdos de Matemática. As escolas participantes da pesquisa bem como o seu Índice de Desenvolvimento da Educação Básica - IDEB são apresentados na Tabela 1.

Tabela 1 -IDEB de 2005 a 2015 - Brasil, Minas Gerais, Uberlândia e das escolas de Uberlândia participantes do trabalho referente ao $5^{\circ}$ ano do Ensino Fundamental.

\begin{tabular}{c|c|c|c|c|c|c}
\hline & \multicolumn{7}{|c}{ IDEB - Índice de Desenvolvimento da Educação Básica } \\
\cline { 2 - 7 } & 2005 & 2007 & 2009 & 2011 & 2013 & 2015 \\
\hline Brasil & 3,8 & 4,2 & 4,6 & 5,0 & 5,2 & 5,5 \\
\hline Minas Gerais & 4,7 & 4,7 & 5,6 & 5,9 & 6,1 & 6,3 \\
\hline Uberlândia & 4,5 & 4,2 & 5,6 & 5,8 & 6,0 & 6,0 \\
\hline Escola Estadual 1 & 5,9 & 5,9 & 7,0 & 6,9 & 7,3 & 7,3 \\
\hline Escola Estadual 2 & 3,9 & 4,7 & 3,3 & 5,7 & 5,7 & 5,9 \\
\hline Escola Municipal 1 & 5,5 & 5,1 & 6,6 & 7,1 & 6,8 & 6,9 \\
\hline Escola Municipal 2 & 3,7 & 3,3 & 5,2 & 4,5 & 5,1 & 4,9 \\
\hline Escola Federal & - & 6,4 & 6,6 & 6,7 & 6,8 & 7,2 \\
\hline Escola Privada 1 & - & - & - & - & - & - \\
\hline Escola Privada 2 & - & - & - & - & - & - \\
\hline Escola Privada 3 & - & - & - & - & - & - \\
\hline Fonte: INEP/MEC. & - & & & \\
* Não foram obtidos os valores do IDEB das escolas privadas.
\end{tabular}

Assim, as instituições de ensino municipais, estaduais e federal foram escolhidas conforme valor do IDEB, utilizando, para tanto, índices abaixo e acima da média nacional para que sejam consideradas diferentes situações de aproveitamento dos alunos. No caso da escola federal esta é considerada de referência na cidade de Uberlândia. Segundo relato das escolas privadas participantes da pesquisa, elas são cadastradas no IDEB, mas não realizam a avaliação.

O IDEB, Brasil (2007), é um indicador de qualidade educacional que combina informações de desempenho em exames padronizados (Prova Brasil ou Saeb), obtido pelos estudantes ao final das etapas de ensino ( $5^{\circ}$ e $9^{\circ}$ anos do Ensino Fundamental e $3^{\circ}$ ano do Ensino Médio), com informações sobre rendimento escolar (aprovação).

Segundo Calderano, Barbaconi e Pereira (2013) as informações obtidas com o IDEB são um retrato do desempenho escolar e não da realidade vivenciada pela escola. Ter um parâmetro para diagnosticar escolas com deficiências no processo de ensino-aprendizagem é louvável, desde que o uso dessas informações seja revertido em intervenções direcionadas às necessidades diagnosticadas.

No tocante às escolas privadas a amostragem escolhida é diversificada, uma vez que utilizou como critérios a oferta dos níveis de ensino, ou seja, escolas que tivessem só o Ensino Fundamental e escolas até o Ensino Médio. A estrutura física também foi pensada, tanto ao pesquisar escolas maiores que tivessem mais demandas e escolas menores. A clientela das escolas diverge, pois, a localização delas é em bairros diferentes. É importante esclarecer que das três escolas privadas, duas são particulares e uma é confessional. Em relação à oferta dos níveis de ensino, duas ofertam todos os níveis da Educação Básica e uma oferta até os anos finais do Ensino Fundamental. São instituições de ensino com mais de vinte anos de existência.

Pretendeu-se, portanto, verificar a percepção dos professores em relação ao ensino de Estatística a partir das seguintes questões: (1) "O que é Estatística para você?"; (2) "Em sua opinião como uma pessoa adquire conhecimento em Estatística?"; (3) "Como você trabalha os conteúdos estatísticos em suas aulas?"; (4) "Como você incorpora situações do cotidiano em suas aulas de Estatística?".

As informações obtidas a partir das respostas às perguntas foram analisadas por meio de análise de conteúdo de Bardin (2009), que é um conjunto de técnicas de análise de comunicação que utiliza procedimentos sistemáticos e objetivos de descrição do conteúdo das mensagens, sendo proposta uma abordagem em três fases:

1. Pré-Análise - organização do material a ser analisado, a fim de torná-lo operacional, sistematizar ideias iniciais;

2. Exploração do material - que define as categorias e identificação das unidades de informação e as unidades de contexto em documentos; 
3. Tratamento dos resultados, inferência e interpretação - que resume as principais informações a partir da análise, culminando em interpretações inferenciais; este é o momento para a intuição, reflexão e análise crítica.

Assim, inicialmente, referindo-se à etapa de Pré-Análise da análise de conteúdo, as questões foram transcritas e lidas a fim de obter uma impressão geral da mensagem e ideias contidas no texto, constituindo-se no corpus da pesquisa.

Com os dados transcritos, explorou-se o material, procedendo-se a uma leitura completa. Em seguida, partindo das questões norteadoras deste trabalho, determinou-se índices ou categorias, e a organização destes em indicadores, subcategorias ou temas.

De acordo com Bardin (2009), as categorias podem ser criadas à priori ou à posteriori, isto é, a partir apenas da teoria ou após a coleta de dados. No caso deste trabalho, foram criadas à priori.

Portanto, para codificar as categorias, para cada questão ou categoria, estabeleceu-se o que se pretendia investigar, ou seja:

1. Para a primeira questão, pretendeu-se investigar como os professores definem os conteúdos estatísticos ou mesmo a Estatística.

2. Para a segunda questão, buscou-se determinar como este grupo de professores acredita que o conhecimento estatístico é adquirido, tendo como objetivo identificar suas percepções sobre o uso de estatísticas.

3. Para a terceira questão, a intenção foi identificar como esses professores percebem seu trabalho com os conteúdos estatísticos em suas salas de aula.

4. Para a quarta questão, procurou-se identificar a percepção do mesmo grupo sobre o papel da utilização de situações do cotidiano no ensino de Estatística.

E a organização em temas ou subcategorias, segundo Bardin (2009, p. 100), foram baseados na frequência com que foram surgindo e então recortadas do texto em unidades comparáveis de categorização para a realização da análise temática e de modalidades de codificação para o registro dos dados.

Portanto, no presente trabalho, o título e a definição da categoria foram estabelecidos tomandose por base as questões propostas e os temas ou subcategorias, a partir das respostas emitidas pelos participantes. Este procedimento segue a sugestão de Mendes (2006, p. 46) que propõe que "o nome e a definição devem ser sempre criados com base nos conteúdos verbalizados e com certo refinamento gramatical de forma. Às vezes, o nome da categoria é uma fala do sujeito". Cabe destacar que em todo o processo procurou-se preservar na íntegra a fala do participante.

Por fim, passou-se à interpretação de conceitos e proposições, pretendendo que as percepções dos professores dessem sentido de referência geral, produzindo uma imagem significativa. Buscouse que as percepções se derivassem da cultura estudada e da linguagem dos participantes, e não exclusivamente da definição científica. Ao se descobrir um tema nos dados, foi preciso comparar enunciados e ações entre si, para ver se existia um conceito que os unificasse. Quando se encontram temas diferentes, foi necessário achar semelhanças que possa haver entre eles.

\section{RESULTADOS}

Para melhor visualizar a apresentação dos relatos dos professores em relação as suas percepções em relação ao Ensino de Estatística utilizamos a seguinte caracterização: (1) professores de Escolas Estaduais (PEE) seguido do número de identificação do professor (por exemplo, PEE1); (2) professores de Escolas Municipais (PEM) seguido do número de identificação do professor (por exemplo, PEM2); (3) professores da Escola Federal (PEF) seguido do número de identificação do professor (por exemplo, PEF3); (4) professores de Escolas Privadas (PEP) seguido do número de identificação do professor (por exemplo, PEP4).

A primeira questão ou categoria tratou do que esse grupo de professores considera e/ou define o que seja a Estatística. Portanto, passamos para a análise de conteúdo destacando oito grandes temas ou subcategorias, Figura 1, e a seguir as falas dos participantes. 
Figura 1 - Como os professores consideram e/ou definem o que seja a Estatística

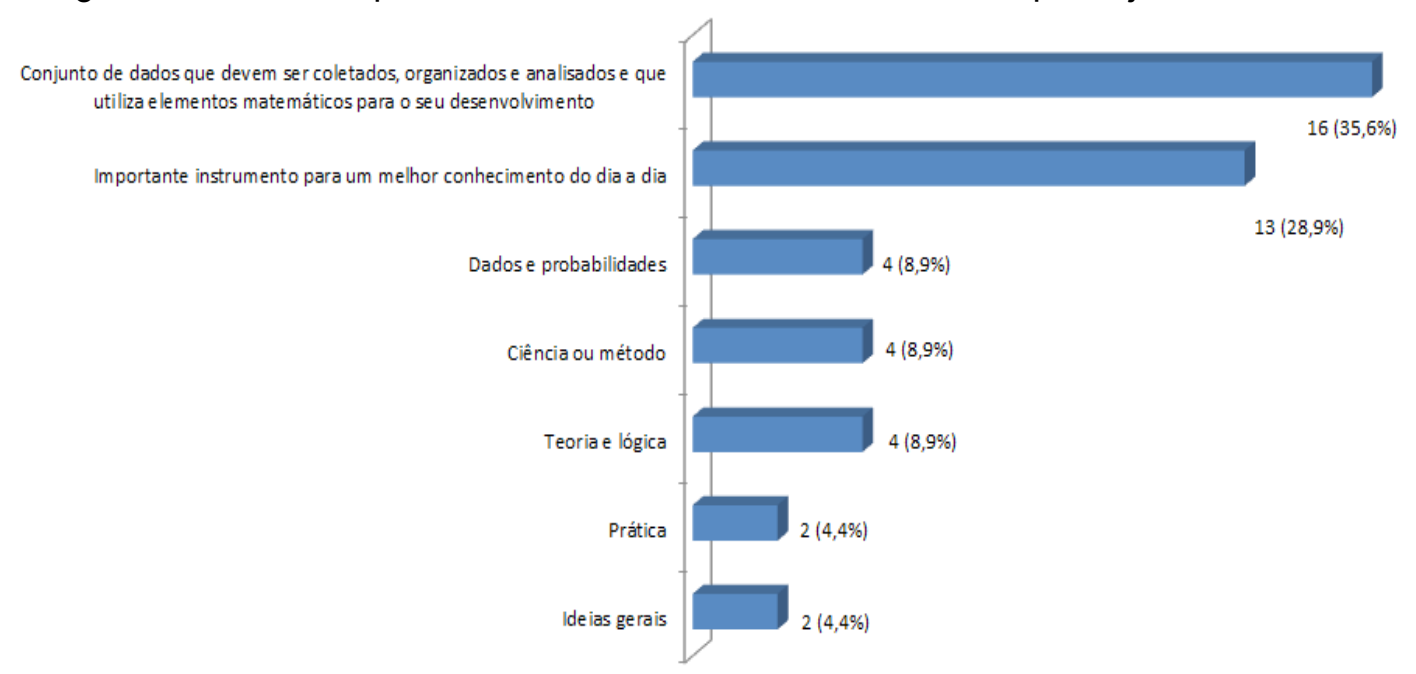

Fonte: Elaborado pelos autores.

Da primeira questão "O que é Estatística para você?", observamos que dentre 45 professores $(81,8 \%)$ do total de 55 professores que a responderam, 35,6\% (16 professores) definiram que a Estatística é um conjunto de dados que devem ser coletados, organizados e analisados e que utiliza elementos matemáticos para o seu desenvolvimento. Apresentamos alguns depoimentos que corroboram este posicionamento:

\section{Estatística é um conjunto de dados. PEE6}

Estatística é uma ciência que contribui, estuda, investiga a organização, representação, comparação, compreensão dos dados, por meio de técnicas e métodos. PEF8

Estatística vai abranger a pesquisa, coleta de dados para determinada questão que utilizará a Matemática para os resultados finais. PEM13

A Estatística, como parte da Matemática, estuda os dados numéricos normalmente sujeitos a variações. PEP14

Observamos que para este grupo de professores o significado de Estatística converge, parcialmente, para o que a nova BNCC, Brasil (2017, p. 10), destaca como o papel da Estatística nos anos iniciais do Ensino Fundamental, ou seja, envolvem o trabalho com a coleta e a organização de dados de uma pesquisa de interesse dos alunos.

Falta para estes professores considerarem o papel da pesquisa realizada pelos próprios alunos. Assim, os alunos deveriam planejar como realizar a pequisa, o que ajudaria na comprensão do papel da estatística no seu cotidiano.

Ainda destacamos um grupo de 13 professores $(28,9 \%)$ que consideram a Estatística como importante instrumento para um melhor conhecimento do dia a dia. Apresentam-se também depoimentos que indicam esta opinião em relação ao que seja "Estatística":

Ciência, área do conhecimento que permite ao indivíduo compreender melhor o mundo a sua volta. PEE7

Estatística é uma disciplina fundamental a diversos assuntos, seja no mundo profissional ou até mesmo no dia a dia. PEM10

É uma forma de aplicar muito da realidade no cotidiano. PEP3

São conhecimentos importantes os quais são utilizados cotidianamente. PEF11

Destacamos a partir do depoimento dos professores que a estatística é um importante meio para compreender e saber os números que explicam nosso mundo. Além deste aspecto, os professores de matemática devem ter em mente a necessidade de fazer crescer o conhecimento estatístico em seus alunos, para que se formem cidadãos capazes de compreender o mundo em torno deles. 
E os depoimentos dos professores corroboram o que traz Lopes (2008) ao destacar a necessidade de se lembrar de que as raízes da Estatística estão centradas nas diferentes áreas do conhecimento e esta percepção remete à interdisciplinaridade.

E estudos internacionais alertam que a prática geralmente tem consequências positivas ao permitir que o aluno coopere com seus pares e se torne um construtor de conhecimento ativo (HUFFMAN; GOLDBERG; MICHLIN 2003; MILLER 2000; BEN-ZVI 2006), pois esta tarefa se assemelha com o que aparece na prática diária, trazendo a sala de aula mais próxima das situações da vida real.

Observa-se que 3 (três) grupos, formado cada um deles por 4 (quatro) professores (8,9\%), destacam o que consideram ser estatística, como: (1) Dados e probabilidades; (2) ciência ou método; (3) teoria e lógica. Apresentam-se relatos que indicam esta opinião em relação ao que seja estatística:

\begin{abstract}
Ciência que se dedica ao agrupamento metódico e ao estudo dos fenômenos que se prestam a adoção numérica. PEP2
\end{abstract}

\begin{abstract}
A Estatística é composta de experimentos, modelos, métodos e outros. PEF3
Partir do simples para o complexo. Respeitar o que o aluno sabe e construir o conhecimento. PEM9
\end{abstract}

Cálculos, quantidade e como mensurar isso; expressão de realidades através de cálculos, porcentagens; entender o mundo através das operações, formas espaciais; raciocínio lógico. PEP9

Segundo os professores, tomando a definição de Triola (1998), a estatística é uma coleção de métodos para planejar experimentos, obter dados e organizá-los, resumi-los, analisá-los, interpretálos e deles extrair conclusões.

Mas acreditamos que esta definição deve ser mais completa, e para tanto, tomamos Matsushita (2010), que define a estatística como um conjunto de métodos e técnicas que envolve todas as etapas de uma pesquisa, desde o planejamento, coordenação, levantamento de dados por meio de amostragem ou censo. E para isso, deve-se realizar a aplicação de questionários, entrevistas e medições com a máxima quantidade de informação possível para um dado custo, a consistência, o processamento, a organização, a análise e interpretação dos dados para explicar fenômenos socioeconômicos, a inferência, o cálculo do nível de confiança e do erro existente na resposta para uma determinada variável e a disseminação das informações.

E ainda mais importante, para Rao (1997), a estatística deve ser definida de uma forma simples e objetiva. Ele a define pela seguinte equação: "Conhecimento incerto + Conhecimento sobre a incerteza = Conhecimento útil". Neste sentido, o objetivo da Estatística é analisar os dados disponíveis e que estão sujeitos a um certo grau de incerteza no planejamento e obtenção de resultados.

Concordamos ainda com Matsushita (2010), de que a Estatística não é somente um ramo da Matemática, mas onde se investigam os processos de obtenção, organização e análise de dados sobre uma determinada população.

Além destes aspectos, segundo o Guidelines for Assessment and Instruction in Statistics Education (GAISE) - Orientações para a avaliação e ensino em Educação Estatística - Report: a Pre-K-12 Curriculum Framework, Franklin et al. (2005), a maior diferença entre a Estatística e a Matemática é que a primeira é uma disciplina metodológica não existindo por si só, apoiando-se em outras áreas de estudo, sendo que o papel da Estatística é disponibilizar ideias coerentes e ferramentas sobre o comportamento dos dados.

Também não se limita a um conjunto de elementos numéricos relativos a um fato social, nem a tabelas e gráficos usados para o resumo, a organização e apresentação dos dados de uma pesquisa, embora seja um aspecto que pode ser facilmente percebido no cotidiano.

Assim, é necessário desenvolver uma prática pedagógica que proponham situações em que os alunos realizem atividades que fazem parte de seu cotidiano, para poderem observar e construir os eventos possíveis, por meio de experimentação concreta, de coleta e de organização de dados. 
Para fechar esta primeira questão, ainda são indicados 2 (dois) grupos compostos cada um deles por 2 (dois) professores (4,4\%) que definiram a Estatística como "Prática" e outro grupo, categorizado como Outros, que a associa à área das Exatas e ser um facilitador da aprendizagem. Realçamos os dizeres dos professores:

\section{Maneira prática de se aprender a resolver desafios matemáticos. PEP4}

Área da exata, não muito agradável para muitos, um desafio. PEE3

Um facilitador de aprendizagem que estimula a criatividade dos alunos. PEM7

Neste último ponto, os professores consideram que através de estratégias didáticas, metodológicos e construtivistas pode-se fazer os alunos compreender os conceitos de estatísticas de uma maneira mais prática e com menos memorização, para que no futuro possam aplicar o que aprenderam. $\mathrm{O}$ aprendizado do aluno pode ser gerado a partir de situações reais que motivem $\mathrm{e}$ despertem seu interesse para a aquisição de novos conhecimentos.

Em Oliveira Júnior et al. (2013), os professores dos anos iniciais do Ensino Fundamental definem Estatística, pensando em coleta, organização e análise de dados, o que converge também para o que este grupo de professores tem como definição de Estatística. E da mesma forma, ficam na dúvida quanto a ser um método, ou técnica, ou uma ciência ou elementos para tomada de decisão ou parte da matemática aplicada, indicando que é necessário um estudo mais aprofundado dos elementos estatísticos.

Assim, a partir dos depoimentos dos professores, estes se aproximam da definição de Estatística segundo o site da Escola Nacional de Ciências Estatísticas ?? ENCE, (INSTITUTO BRASILEIRO DE GEOGRAFIA E ESTATÍSTICA, 2014), onde se define "estatística" como um conjunto de técnicas e métodos de pesquisa que entre outros tópicos envolve o planejamento do experimento a ser realizados, a coleta qualificada dos dados, a inferência, o processamento, a análise e a disseminação das informações.

Além disso, esta definição, a nosso ver, traz aspectos importantes sobre o que é estatística, mostrando que além de ser um conjunto de técnicas e métodos, envolvem aspectos como a coleta, tratamento, apresentação e análise de dados que são importantes para auxiliar na tomada de decisão em diversas áreas do conhecimento, sendo ainda, útil para o nosso cotidiano.

E a tomada de decisão segundo autores brasileiros e internacionais que foram citados no referencial deste trabalho, consideram os saberes estatísticos como ferramentas essenciais para a tomada de decisão no mundo contemporâneo e que devem integrar os currículos escolares desde os anos iniciais de formação (BATANERO; 2001; ESTRADA; BAZÁN; APARICIO, 2010; ESTRADA; BATANERO, 2008; LOPES, 2008; 2010; LOPES et al., 2010).

A segunda questão ou categoria trata-se de como o grupo de professores de escolas públicas e privadas considera que uma pessoa adquire conhecimentos em Estatística, bem como os temas ou subcategorias que emergiram de suas falas, Figura 2.

Figura 2 - Como os professores consideram que se adquirem conhecimentos em Estatística

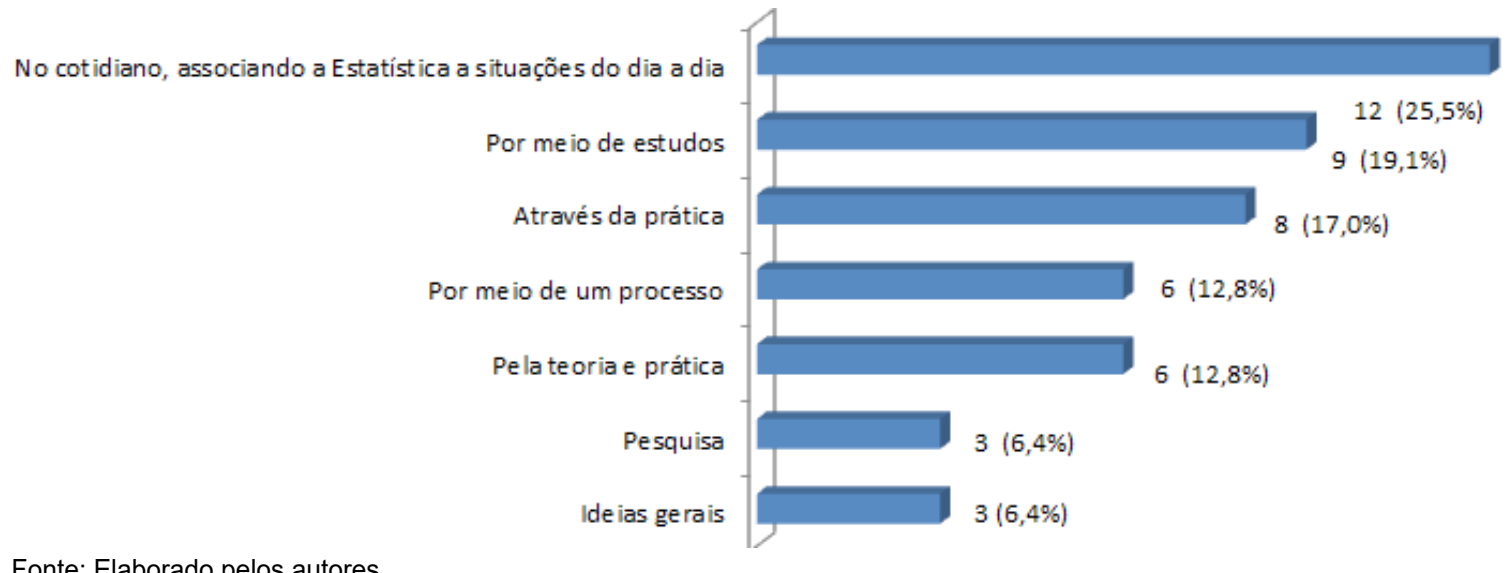

Fonte: Elaborado pelos autores. 
Destaca-se que $25,5 \%$ destes professores acreditam que se adquire este conhecimento no cotidiano, associando a Estatística a situações do dia a dia. Para um melhor entendimento, destacamos as seguintes falas:

\title{
Na escola e no dia a dia. PEM10
}

Enquanto estudante é diretamente influenciado pela escola que dependendo de sua concepção pode despertar o olhar para a presença da Matemática na vida cotidiana. Como cidadão é necessário adquirir no cotidiano conhecimentos relacionados a própria dinâmica diária. PEF1

Com as vivências do dia a dia, vinculadas às explicações em sala de aula, estruturando o saber mais formal. PEP15

Este grupo de professores acredita importante que o aluno levante dados de situações de seu cotidiano, organize os dados, calcule as medidas necessárias, possa discutir os resultados, analisar a estratégia utilizada, verificar existência de erros e, efetuar análises dos resultados obtidos. E acreditamos que nesse contexto o aluno passa a desenvolver sua criticidade e outras habilidades, na perspectiva da Educação Estatística.

O posicionamento deste grupo de professores converge para afirmação de Lopes $(2008$, p. 2) quando destaca que é essencial à formação dos alunos o desenvolvimento de atividades estatísticas que partam sempre de uma problematização, pois assim como os conceitos matemáticos, os estatísticos também devem estar inseridos em situações vinculadas ao cotidiano deles.

E o estudo de Oliveira Júnior et al. (2013), conclui que para a maioria dos professores a estatística é uma ciência exata, que lida com números, gráficos e tabelas, auxilia na interpretação das informações do dia a dia e é importante no cotidiano. O que converge, para as percepções deste grupo de professores, principalmente em relação a convergir para a utilização de situações do dia a dia.

Ainda trazemos Corrêa (2012), que em sua pesquisa sobre percepção de professores em relação ao ensino da Estatística, percebeu-se que todos atribuem à Estatística um lugar de relevância, justificando que conhecimentos estatísticos são importantes, pois estão presentes no cotidiano dos alunos.

Destacam-se também aqueles professores (19,1\%) que entendem que se adquire conhecimento estatístico por meio de estudos. Apresentam-se os seguintes testemunhos que indicam este pensamento:

\begin{abstract}
Estudando, claro, compreendendo os caminhos de raciocínio das mesmas e principalmente no fato de saber usá-las em seu cotidiano, entendendo como a Estatística é importante nos mais diferentes aspectos de vivência no dia a dia. PEE7
\end{abstract}

Estudando e buscando conhecimento, começando da base. PEP7

Através de estudos, leituras, esforço e interesse. Capacidade de procurar novos caminhos, novas resoluções, novos dados. PEM4

Estudar implica ter que se envolver ativamente com os conteúdos e para que não seja um mero receptor de informação durante as aulas. É necessária a condução do processo de aprendizagem da melhor maneira para uma maior apreensão dos conteúdos a serem aprendidos, especificamente, os conteúdos estatísticos.

E para fundamentar o posicionamento deste grupo de professores dos anos iniciais, trazemos Freire (1974), que destaca que o sujeito da ação de estudar é o aluno, valorizado em sua individualidade, de quem se exige uma postura crítica e uma inserção na realidade. O estudante toma decisões e age, fundamentado na análise de uma realidade que transcende os limites tradicionais (escola, livro, professor, por exemplo). Dessa forma, o modo como o aluno percebe o estudar vai determinar uma série de outras ações quanto à busca e ao tratamento de informações, gerando conseqüências no seu agir.

Outra categoria de professores $(17,0 \%)$ respondeu que é por meio da Prática que se adquire conhecimentos estatísticos. Para melhor explicitar estas opiniões, apresentamos alguns depoimentos: 
Através do concreto, com jogos, brincadeiras, exemplificações entre outras situações. PEM6

Eu acredito que a Estatística e também a Matemática é claro, é preciso que o aluno vivencie algo concreto, ou seja, experencie esse conhecimento para que ele veja algo real. PEE12 Através da prática contínua. PEP15

Este grupo de professores considera que o estudo da estatística permite ampliar a imagem que os alunos desenvolvem sobre a Matemática através da contextualização das aprendizagens e da sua ligação à realidade. E Batanero (2001) expressa que não se requer procedimentos matemáticos muito sofisticados, pois a estatística proporciona múltiplas aplicações da Matemática para resolver problemas reais em contextos diversificados.

Dois grupos de professores, representados por $12,8 \%$ cada, sinalizaram que os conhecimentos estatísticos são adquiridos por meio de um Processo e também pela Teoria e Prática. Alguns discursos esclarecem melhor essas ideias:

\section{É um processo de aprendizado adquirido ano a ano. PEE6}

Pensar a Matemática de forma contextualizada, na interação desenvolvida por um aluno e em situação de ensino, o professor é o mediador, relacionar conhecimentos anteriores com novas situações apresentadas, reelaborando ideias. PEP6

Nós aprendemos de diferentes formas, depende do contexto e da iniciativa do professor em motivar o aluno para que este tenha interesse em aprender. PEM7

Acredito que primeiramente este conhecimento é intuitivo, adquirido através das necessidades do dia a dia de contar, enumerar, calcular, etc. com a Estatística também aprendemos quando temos que coletar e organizar informações. Depois formalizamos na escola. PEF4

No estudo de Colodel e Brandalise (2010) estes alertam que os conteúdos matemáticos referentes ao bloco Tratamento da Informação dos PCN estão presentes nas práticas pedagógicas da maioria dos professores, porém apontam a necessidade de auxílio e orientações para o bom desenvolvimento de habilidades e competências matemáticas com os alunos. Assim, cabe uma melhor formação deste grupo de professores.

Partimos também do trabalho de Albuquerque et al. (2007) para sintetizar o depoimento deste grupo de professores em relação aos saberes ou conhecimento estatísticos essenciais para se aprenda estatística, ou seja: (1) deve-se planejar um estudo; (2) desenvolver grupo de discussão do estudo; e então (3) obter as conclusões.

Acreditamos, a partir da fala dos professores, que o planejamento é necessário para compreender o objeto do estudo, delinear os procedimentos de coleta de dados, criar e organizar conjuntos de dados e refletir sobre eles e agir em conformidade.

A descrição dos dados exige compreender a forma como esses dados se distribuem, apoiandose nas medidas de localização e medidas de dispersão, utilizando diferentes formas de percepção ou procurando correlações.

Relativamente à obtenção de conclusões, é importante saber selecionar as representações e medidas mais adequadas para comunicar as conclusões, analisando possíveis causas de variabilidade e compreendendo as dificuldades que surgem na escolha da amostra e na inferência das conclusões para a população.

Para finalizar esta questão ainda temos dois grupos de professores $(6,4 \%$ cada) que citaram a Pesquisa e Outros como sendo elementos necessários para obter conhecimentos que envolvem a Estatística. Seguem algumas falas que contribuem para um melhor entendimento:

Através de pesquisas e coleta de dados. PEP1

Fazendo exercícios e pesquisa, procurando trazer esses conhecimentos para a vida real, mostrando como a Matemática está presente em nossas vidas. PEM13

Compreendendo e concentrando, aprendendo de uma forma prazerosa. PEE5

$\mathrm{Na}$ escola, nos cursos e pela necessidade de cada um, interesse ou necessidade profissional. PEF6 
Consideramos que para este grupo de professores, o aluno deve desenvolver projetos, pois quanto mais ele tomar o projeto para si, isto é, quando estiver envolvido e querendo alcançar o objetivo final do projeto, mais ele se apropria deste conhecimento.

E nos fundamentamos em Machado (2004) quando afirma que o homem é um ser capaz de projetar. E quanto mais desenvolvida for sua razão, mais e melhor ele projeta, cria expectativas e desenvolve situações que o levam ao alcance do objetivo desejado.

Portanto, consideramos que é importante que os alunos deem sugestões nos projetos que lhe forem propostos e façam modificações de acordo com seus interesses. Essa é uma das formas de se manterem motivados e empenhados na busca das respostas que o projeto pode oferecer.

Desta forma, o contato direto dos estudantes com dados reais, auxilia o efetivo aprendizado dos conceitos estatísticos, além de permitir uma melhor reflexão sobre sua utilização.

Continuando a análise, temos agora a terceira questão ou categoria que trata de quais são os procedimentos metodológicos utilizados por esse grupo de professores durante as suas aulas de conteúdos estatísticos. Assim, na análise das suas falas, destacamos sete grandes subcategorias que podem ser evidenciadas na Figura 3.

Figura 3 - Procedimentos metodológicos utilizados por esse grupo de professores durante as suas aulas de conteúdos estatísticos.

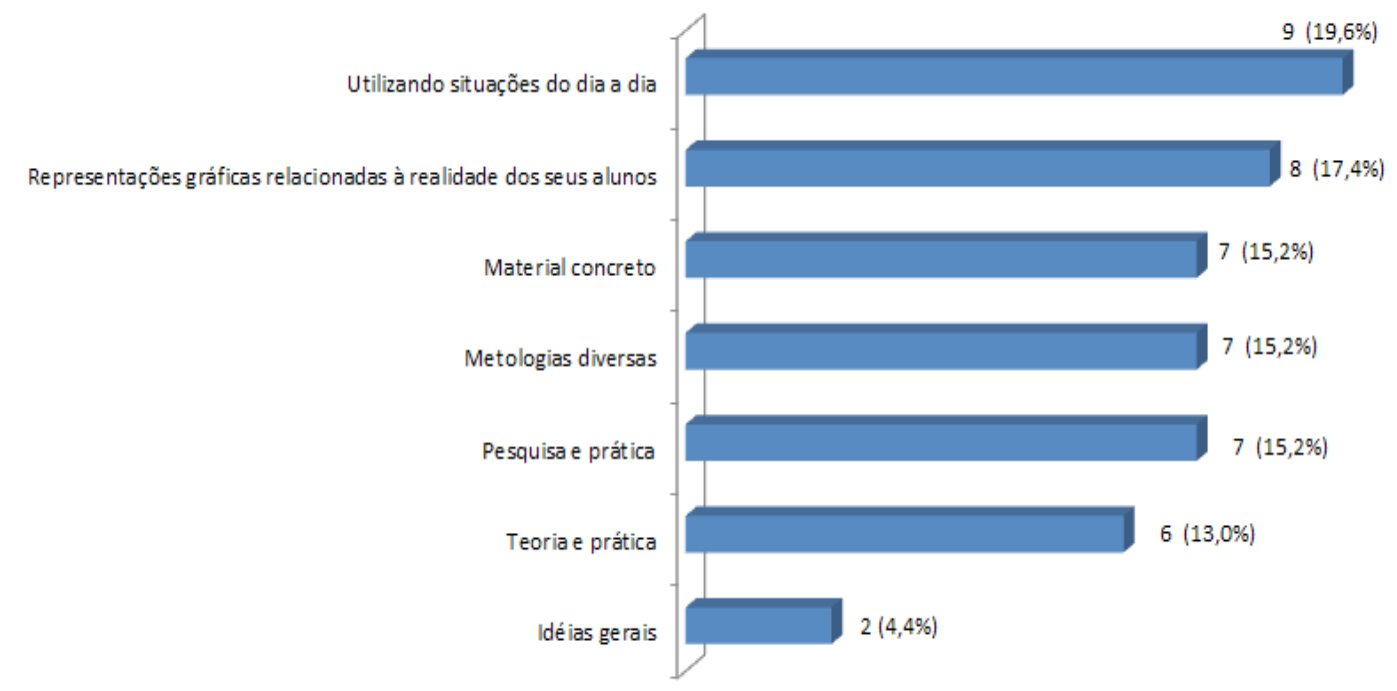

Fonte: Elaborado pelos autores.

Verifica-se que $19,6 \%$ dos professores demonstraram que o vínculo com o dia a dia e com o cotidiano é uma estratégia importante para o processo de ensino-aprendizagem conforme os seguintes relatos:

Primeiramente partindo do pressuposto de que as crianças já sabem. Depois instigo as mesmas a pensar além, refletir onde podemos usar estas ciências, no que são importantes para o nosso dia a dia e assim introduzo novos conhecimentos, trazendo sempre para a realidade vivenciada pela criança. PEE7

Gosto muito de trazer atividades concretas como, por exemplo: medidas de capacidade, massa e comprimento é mais fácil e o aluno aprende usando coisas do dia a dia. Trabalho com rótulos e pesquisas, eu acho muito valioso. PEM14

O mais próximo possível da realidade, de situações reais. PEF4

De forma lúdica relacionando com a vida da criança. PEP14

Segundo Lopes (2008), é necessário o desenvolvimento de práticas pedagógicas envolvendo situações em que os estudantes realizem atividades considerando seus contextos e que estes possam observar e construir os eventos possíveis, por meio de experimentação concreta, de coleta e de organização de dados. 
E partindo de que a estatística está presente em quase todas as atividades do nosso dia a dia, configura-se a importância deste ensino na vida escolar dos alunos e desta temática associada a várias outras áreas do conhecimento.

Desta forma, permitem que os professores levem para sala de aula uma metodologia diferenciada, que envolva os estudantes com fatos do seu cotidiano e/ou presentes nos diferentes meios de comunicação, tais como jornais, revistas, pois são dados obtidos em situações da atualidade.

Outra categoria $(17,4 \%)$ em destaque para esta questão refere-se aos professores que trabalham a Estatística a partir de representações gráficas relacionadas à realidade dos seus alunos. Indicamos algumas declarações para explicitar melhor estas práticas:

Material concreto, dados, informações, gráficos, etc. PEE6

Como ministro aulas para o Ensino Fundamental ( $1^{\circ}$ ao $5^{\circ}$ ano) trabalho com gráficos oriundos de pesquisas relacionadas à realidade do aluno. PEM4

Através de tarefas e gráficos. PEP11

Com gráficos, tabelas em data show e na lousa. PEF12

Destaca-se que os professores consideram que os saberes estatísticos são expressos em gráficos e tabelas, requerendo conceitos estatísticos para a sua interpretação.

A utilização de análise gráfica e a geração de tabelas e gráficos em propostas de sala de aula por parte de alguns professores participantes deste estudo convergem para o estudo de Mendes (2003) quando expõe que é possível ensinar os alunos a coletar dados e construir gráficos já nos anos iniciais.

Estes depoimentos ainda convergem para Brasil (2017, p. 10), na nova Base Nacional Comum Curricular - BNCC, quando é sugerida a leitura, a interpretação e a construção de tabelas e gráficos como papel fundamental para o processo ensino e aprendizagem da Estatística, bem como a forma de produção de texto escrito para a comunicação de dados, pois é preciso compreender que o texto deve sintetizar ou justificar as conclusões.

E ainda alertamos para o fato de que ao assistir a telejornais ou ler jornais, revistas e outros materiais fornecidos pela mídia, observam-se vários tipos de gráficos e tabelas, bem como a grande variedade de informações que apresentam.

E ainda destacamos que é possível verificar sua utilidade e importância, pois tais instrumentos estatísticos facilitam e torna mais ágil a interpretação das informações que veiculam, posto que, por meio de suas ilustrações, possibilita aos meios de comunicação despertar a curiosidade dos leitores e ouvintes.

E Lopes et al. (2010), referencial trazido neste trabalho, corroboram a posição deste grupo de professores, quando indica que deve ser incentivada a leitura e a interpretação de gráficos, de tabelas e de outras medidas estatísticas. E estes dados poderiam ser buscados nos diversos meios de comunicação, a fim de que o aluno saiba posicionar-se de forma crítica diante dessas informações e fornecer-Ihes ferramentas para arguir e desmantelar informações porventura falaciosas ou mal intencionadas.

Outros 3 (três) grupos de professores esclareceram que trabalham a Estatística a partir de: (1) Material concreto (15,2\%); (2) Metodologias diversas (15,2\%); (3) Pesquisa e prática (15,2\%). Indicamos alguns posicionamentos relatos que indicam esta visão:

Com materiais concretos, a partir do conhecimento já existente e ciente que precisam do concreto para entender um pouco do abstrato. PEE5

Introduzindo as bases como conhecimento e buscando no dia a dia como exercício (link, jogo, exercícios de fixação e aulas vídeo). PEP7

Com exercícios de fixação sobre o conteúdo, aulas expositivas, jogos e experimentos. PEM8

Em tabelas e gráficos com interesses da própria turma, com os exercícios propostos nos livros didáticos, coletando informações sobre um determinado assunto ou problema, organizando e representando na forma dessas tabelas ou gráficos e mostrando aos alunos como interpretá-los. Propondo relatórios acerca dos conhecimentos adquiridos a partir das conclusões obtidas por meio dessas tabelas. PEF6 
Estes depoimentos convergem, em linhas gerais, para o estudo desenvolvido por Rocha (2000), pois o autor afirma que logo nos primeiros anos de escolaridade as crianças podem propor questões para investigar, organizar as respostas e criar representações de dados. A autora destaca que através dos dados e suas investigações, as crianças desenvolvem conceitos referentes à tomada de decisão, e que alguns meios e ferramentas estatísticas ajudarão os alunos a formar e a desenvolver as suas capacidades matemáticas.

E trazemos também Santos, Ortigão e Aguiar (2014), que em seu estudo destacam que alguns professores se apoiam em atividades propostas nos roteiros dos livros didáticos, em detrimento de atividades em que levem o aluno a buscar seus próprios dados e então tirar conclusões a partir destes.

Ainda nos fundamentamos na BNCC, Brasil (2017, p. 10), que propõe que todos os cidadãos precisam desenvolver habilidades para coletar, organizar, representar, interpretar e analisar dados em uma variedade de contextos, de maneira a fazer julgamentos bem fundamentados e tomar as decisões adequadas. Isso inclui raciocinar e utilizar conceitos, representações e índices estatísticos para descrever, explicar e predizer fenômenos.

Assim, ao ensino de Matemática fica o compromisso de não só ensinar o domínio dos números, mas também a organização de dados e a leitura de gráficos. Ao professor de Matemática, cabe não se limitar à mera transmissão de fórmulas e algoritmos, mas deve dar sentido e vida a essa matemática escolar que, embora pareça distante, se faz cada vez mais necessária.

Desta forma, o papel do professor no processo ensino-aprendizagem da Estatística deve partir de uma metodologia por meio da proposição de problemas concretos e da realização de experimentos reais, favorecendo a formação do aluno num desenvolvimento a caminho da cidadania.

Finalizando a terceira questão, dois grupos de professores afirmaram que trabalham os conteúdos estatísticos por meio da Teoria e Prática $(13,0 \%)$ e com outros métodos $(4,4 \%)$ conforme os relatos a seguir:

\section{Com teoria e prática. PEE14}

Com gráficos, tabelas, situações problemas, gravuras, operações, atividades práticas (laboratórios), atividades que estimulem o cálculo mental. PEP9

Considerando a fundamentação teórica a qual utilizo no meu trabalho, considero que o conhecimento matemático está relacionado a manipulação concreta, até que se desenvolva o conceito e não seja mais necessária a manipulação, conceitos mais abstratos são construídos com os mais simples que por conseguinte foram construídos pela manipulação de materiais. PEF2

Todo meu trabalho é realizado dentro de um contexto e procuro realizá-lo sempre de forma interdisciplinar. PEM7

Observamos também que recai sobre o professor, principalmente, o papel de ensinar esses conteúdos estatísticos aos alunos. E, como sabemos, um dos principais recursos de ensino utilizados pelo professor é o livro didático, recurso que se configura numa das poucas formas de documentação e de consulta usada por professores e alunos nas escolas públicas (BRASIL, 2004).

E como descreve Lopes (2008) é essencial à formação de nossos alunos o desenvolvimento de atividades estatísticas que partam sempre de uma problematização, pois assim como os conceitos matemáticos, os estatísticos também devem estar inseridos em situações vinculadas ao cotidiano deles.

E para que ocorra a articulação entre diversos conteúdos torna-se necessário realizar um ensino interdisciplinar, na medida em que o aluno irá pesquisar, investigar e coletar dados sobre diversos temas.

Consideramos que o ensino da estatística deve ser realizado a partir de problematizações, onde o aluno será orientado a refletir sobre questões provocadoras, que o ajudará a introduzir operações básicas e representações gráficas, sendo uma boa maneira de desencadear o trabalho interdisciplinar em sala de aula. 
Assim, é preciso propiciar conhecimentos e habilidades fundamentais ao aluno para ser possível a realização de leituras, a resolução dos cálculos e a interpretação de dados, bem como a estruturação e contextualização destes na escola.

Partindo do princípio de que a Estatística deve ser aplicada no dia a dia, pois é uma ciência que está a serviço das demais além de ser um tema interdisciplinar, a última categoria desta análise da percepção dos professores questiona se estes incorporam situações do cotidiano em suas aulas de Estatística, e de que forma. Portanto, a partir da análise das suas falas, destacamos cinco grandes temas ou subcategorias que podem ser evidenciadas na Figura 4.

Figura 4 - Maneira como os professores incorporam situações do cotidiano em suas aulas de conteúdos estatísticos.

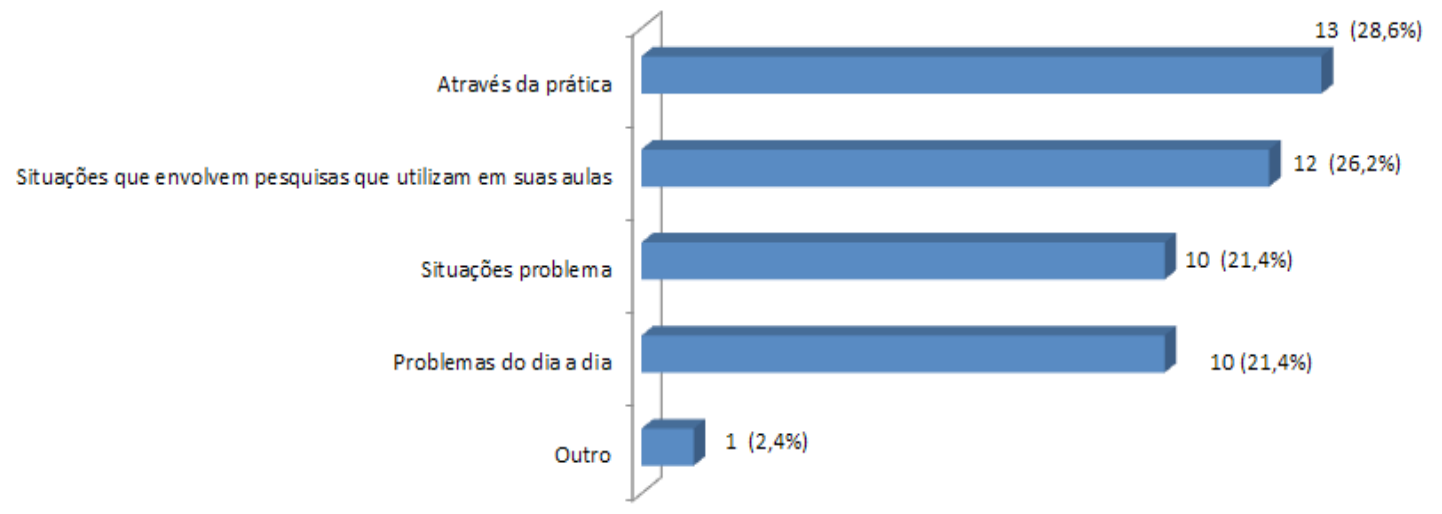

Fonte: Elaborado pelos autores.

Os relatos a seguir, demonstram como 13 professores $(28,6 \%)$ incorporam a Estatística em suas aulas por meio da prática:

Usando exemplos práticos, dentro da compreensão deles, usando uma linguagem adequada ao que propomos dentro de cada aula. PEM7

\begin{abstract}
Analisando situações problema de acordo com a faixa etária, montando mercado com sucata para trabalhar dinheiro (valor, troco, adição, subtração). Contando objetos, medindo espaços com diversos materiais como régua, fita métrica, trena etc. Investigando as possíveis respostas para medir determinado espaço, etc. PEP12

Por exemplo, podemos trabalhar com estatísticas de situações de interesse da própria turma com uma simples tabela de preferências em relação a comida, time de futebol, brincadeira, ou de probabilidades de acerto em uma prova ou atividade ou tarefa de casa. Trabalhar com lista de idades, tamanho e peso das crianças colocando em tabelas ou fazendo gráficos de situações do cotidiano da sala. PEF6
\end{abstract}

Acredita-se que uma forma de se adquirir o conhecimento estatístico é por meio da junção de metodologias como a contextualização com o cotidiano do aluno, com temas atuais e trazendo a prática, por exemplo, a partir do desenvolvimento de pesquisas.

Este grupo de professores concorda com Miguel (2003) quando expõe que o conhecimento matemático não se consolida como um rol de ideias prontas a serem memorizadas. Deve ser um processo significativo de ensino que conduza os alunos à exploração de uma grande variedade de ideias e de estabelecimento de relações entre fatos e conceitos de modo a incorporar os contextos do mundo real, as experiências e o modo natural de envolvimento para o desenvolvimento das noções matemáticas com vistas à aquisição de diferentes formas de percepção da realidade.

Nesta mesma questão, $26,2 \%$ dos professores destacam situações que envolvem pesquisas que utilizam em suas aulas, quais sejam:

Através de questionário e pesquisa com os alunos. PEE6

Trabalhando pesquisa, ex: filme preferido dos alunos, lanche preferido, contas de boleto, supermercado e outros. PEM11 
A partir das investigações/curiosidades da turma. Por exemplo: tabela elaborada a partir de características físicas dos alunos. Gráfico sobre os personagens preferidos da turma da Mônica, dentre outros. PEF12

Para Silva (2007) trabalhar a Estatística por meio de projetos ou o desenvolvimento de uma pesquisa, objetiva que o estudante sinta necessidade de resolver um problema, o que poderá garantir seu envolvimento. Dessa forma, o problema deixaria de ser resolvido apenas porque o professor o pede, pois, o estudante estando envolvido, passaria a desejar a solução e buscaria ferramentas necessárias para isso.

Onuchic e Allevato (2009) defendem que o problema é ponto de partida para se alcançar o conhecimento e posicionam o professor como guia e o aluno como co-construtor nos processos de ensino-aprendizagem. Neste sentido, 2 (dois) grupos de professores (21,4\% cada) afirmam que por meio de situações problemas e do dia a dia é possível incorporar circunstâncias do cotidiano nas aulas que envolvem os conteúdos estatísticos. Algumas respostas expressam melhor o pensamento dos professores:

Através de rodas de conversa colhendo informações necessárias para o desenvolvimento do trabalho em sala de aula. PEM4

Gosto muito de trazer atividades concretas como, por exemplo, medidas de capacidades, massa, comprimento é mais fácil o aluno aprende usando coisas do dia a dia. Trabalho com rótulos e pesquisas, acho muito valioso. PEE12

Por considerar que os conhecimentos advindos de situações cotidianas não devem ser separados, os mesmos não são incorporados, fazem parte da aula naturalmente. PEF2

Gal (2002) aponta os estudos estatísticos como ferramentas importantes para a formação de um cidadão capacitado a resolver situações-problema que estão presentes em seu cotidiano com melhor desempenho.

Assim, consideramos que para que o ensino da estatística possa de fato contribuir para a formação cidadã é importante que se possibilite ao aluno o confronto de problemas estatísticos com o mundo real, desafiando-os a encontrar soluções e estratégias para resolver os problemas que lhes são apresentados.

O aluno pode aproveitar fatos, situações e questionamentos do cotidiano para estudar, avaliar, analisar e encontrar resultados. Sendo assim, ele se sentiria motivado, e fazendo parte do processo o que facilita a aprendizagem e o torna um ser responsável pelo mundo onde está inserido.

$\mathrm{E}$ assim, sugerem aos professores que incentivem os alunos a observar os fenômenos, conjeturar hipóteses, fazer levantamento de dados, tratá-los e analisá-los do ponto de vista da investigação científica.

\section{CONSIDERAÇÕES FINAIS}

Os conteúdos estatísticos começaram a fazer parte dos currículos de matemática do Ensino Fundamental a partir de 1997 com a publicação dos PCN, e, ainda representa um assunto novo para muitos professores, tornando-se um desafio desenvolver com os estudantes, atividades contendo aspectos didáticos me relação aos conteúdos estatísticos.

Os PCN, Brasil (1997), enfatizam a necessidade de se iniciar o estudo de conhecimentos estatísticos a partir dos anos iniciais do Ensino Fundamental devido a: (1) Constante utilização na sociedade atual; (2) Necessidade de o indivíduo compreender as informações vinculadas pelos meios de comunicações; (3) Tomada de decisões e a realização de previsões que influenciam na vida individual e coletiva.

Em síntese, este trabalho pode trazer contribuições para a melhoria da formação de professores de Matemática na medida em que os professores participantes desta pesquisa expressam suas percepções em relação ao Ensino de Estatística.

Assim, na primeira categoria, os professores definem a Estatística como um conjunto de técnicas e métodos de pesquisa que entre outros tópicos envolve o planejamento do experimento a ser realizadas, a coleta dos dados, o processamento, a análise e a tomada de decisão. Esta definição converge para estudos nacionais e internacionais, considerando os seguintes aspectos: 
a) Os saberes estatísticos tornam-se ferramentas essenciais para a tomada de decisão no mundo contemporâneo, segundo Batanero (2001), Estrada, Bazán e Aparicio (2010), Estrada e Batanero (2008), Lopes (2008; 2010) e Lopes et al. (2010).

b) Desenvolver no aluno a habilidade de coletar, organizar e interpretar os dados, segundo Mendes (2003), Lopes (2008), Oliveira Júnior et al. (2013), Instituto Brasileiro de Geografia e Estatística (2014) e Brasil (2017).

No entanto, os professores não abordam aspectos quanto à inferência, ou seja, que a partir da coleta de dados amostrais, possa tirar conclusões para a população; considere que os dados são gerados a partir de fatores aleatórios; e abordar o conceito de incerteza; como os estudos de Rao (1997), Franklin et al. (2005) e Matsushita (2010).

Considerando a segunda categoria, os professores procuram ensinar os conteúdos estatísticos relacionando-os com dados utilizados no cotidiano do aluno, por exemplo, em informações veiculadas pelos jornais e a mídia em geral, constituindo-se numa "alavanca" geradora de motivação para a aprendizagem do conteúdo estatístico ou vinculam o ensino utilizando elementos práticos do dia a dia do aluno ou elementos de interesse do mesmo.

As práticas desses professores convergem para o que dizem Miller (2000), Huffman, Goldberg e Michlin (2003) e Ben-Zvi (2006), quando alertam que a prática gera consequências positivas ao permitir que o aluno coopere com seus pares e se torne um construtor de conhecimento ativo, pois esta tarefa se assemelha com o que aparece na prática diária, trazendo a sala de aula mais próxima das situações da vida real.

No estudo de Oliveira Júnior et al. (2013) quanto à forma como professores dos anos iniciais trabalham os conteúdos estatísticos em sala de aula, alguns deles tomam tabelas e gráficos e associam a situações do cotidiano, mas a maioria não sabe como apresentar estes conteúdos. Estes resultados convergem para o que se percebeu na fala dos professores participantes deste estudo. Parece que os professores consideram que somente a análise ou elaboração de gráficos e tabelas são necessárias e suficientes para o ensino dos conteúdos estatísticos.

Além disso, os estudos de Colodel e Brandalise (2010) e Bessa e Leite (2015), indicam o que percebemos neste trabalho, ou seja, os professores inserem em sua prática os conteúdos estatísticos e reconhecem o valor e a importância da estatística e da matemática para a vida, no entanto, não têm uma explicação clara para isso, indicando que necessitam de formação continuada para trabalharem com os conceitos estatísticos.

Em relação à terceira categoria, parecem acreditar que o conhecimento deve ser construído pelos estudantes à medida que as atividades didáticas fazem uso de significados lógicos, de ideias relevantes, como também, de ideias que já se encontram disponíveis na estrutura cognitiva deste. A partir disto, os conteúdos escolares se relacionariam com a prática e cotidiano dos alunos, possibilitando aos mesmos atribuírem sentido ao que lhes é ensinado.

Finalmente considerando a quarta e última categoria, acreditam que por meio do uso de dados reais, os estudantes aprendem pela análise de dados que é parte integrante dos processos de pesquisa e não uma série de dados isolados. Além disso, com a utilização de dados reais, os estudantes devem ser pesquisadores, (não os objetos de estudo) e eles devem coletar dados por si próprios ou participar no delineamento do instrumento de coleta de dados.

Nas duas últimas categorias, estas convergem para estudos de Gal (2002); Miguel (2003); Lopes (2008); Corrêa (2012); e Oliveira Júnior et al. (2013) que indicam haver a necessidade de que haja a incorporação de contextos voltados ao mundo real, ou seja, situações vinculadas ao cotidiano dos alunos e que sejam desenvolvidas atividades estatísticas que partam sempre de uma problematização.

E, considerando Lopes (2008) e Guimarâes et al. (2009), ainda faz-se necessário repensar a formação inicial e continuada dos professores que lecionam Matemática na Educação Básica e tornar possível a divulgação dos saberes produzidos na escola para atingir a alfabetização estatística. E, conhecer as percepções dos professores, pode ajudar a planejar programas de educação continuada para professores da Educação Básica e fornecer indicadores de melhoria na qualidade de ensino quanto à formação inicial.

Portanto, ensinar hoje é um desafio constante e uma tarefa complexa para todos os profissionais envolvidos no âmbito escolar, devido, principalmente, à nova relação estabelecida entre o professor e o conhecimento. 
Cotidianamente, professores e alunos são bombardeados por inúmeras informações, oriundas de diversas fontes, como jornais, revistas, propagandas, televisão, internet, dentre outros, e nem sempre são de fontes confiáveis. Paralelamente, com a diversidade de informações, existe a necessidade de tomar decisões eficazes que garanta uma participação ativa nessa sociedade atual. É nesse sentido que o ensino de Estatística, desde os anos iniciais do Ensino Fundamental, torna-se uma exigência para a escola inserida no mundo das informações.

$\mathrm{E}$, mais uma vez, surge a inquietação no que tange à formação do professor polivalente, uma vez que a sua formação matemática inicial não tem incorporado um trabalho sistemático sobre a Estatística, dificultando a possibilidade desses profissionais desenvolverem um trabalho que promova o letramento estatístico desde os anos iniciais. 


\section{REFERÊNCIAS}

ALBUQUERQUE, C. et al. A Matemática na formação inicial de professores. Lisboa: Associação de Professores de Matemática \& Secção de Educação e Matemática da Sociedade Portuguesa de Ciências da Educação, 2007. p. 90-95. Disponível em: <http://www.apm.pt/files/_90-95_lq_45d9e33dcb34b.pdf>. Acesso em: $07 \mathrm{dez} .201 \overline{6}$.

BARDIN, L. Análise de Conteúdo. Lisboa, Portugal: Edições 70, LDA, 2009.

BATANERO, C. Didáctica de la Estadística. Granada: Universidad de Granada, Espanha, 2001. Disponível em: <http://www.ugr.es/ batanero/pages/ ARTICULOS/didacticaestadistica.pdf>. Acesso em: 21 out. 2016.

BEN-ZVI, D. Scaffolding students' informal inference and argumentation. In ROSSMAN, A.; CHANCE, B. (Eds.). International Conference on Teaching Statistics, 17., 2006. Proceedings... Voorburg, The Netherlands: International Statistical Institute, 2006. Disponível em: <https://www.stat.auckland.ac.nz/ iase/publications/17/2D1_BENZ.pdf>. Acesso em: 15 nov. 2017.

BESSA, S.; LEITE, E. C. Percepções dos professores da Educação Básica sobre ensino-aprendizagem de matemática. In: Congresso Nacional de Educação, 20., 2015. Anais... EDUCERE, Pontifícia Universidade Católica do Paraná, Curitiba, 26 a 29 out. 2015.

BRASIL. Base Nacional Comum Curricular. Ministério da Educação, abril 2017. Disponível em: <http:// www.observatoriodoensinomedio.ufpr.br/wp-content/uploads/2017/04/BNCC-Documento-Final.pdf>. Acesso em: 30 jun. 2017.

BRASIL. Índice de desenvolvimento da Educação Básica, 2007. Disponível em: <http://portal.mec.gov. br>. Acesso em: 20 dez. 2012.

BRASIL. Ministério da Educação e do Desporto. Guia de livros didáticos: $1^{\text {a }}$ a $4^{\text {a }}$ séries. Brasília: MEC, 2004.

BRASIL. Ministério da Educação e do Desporto. Secretaria de Educação Fundamental. Parâmetros curriculares nacionais primeiro e segundo ciclos do Ensino Fundamental: Matemática. Brasília: MEC/ SEF, 1997.

CALDERANO, M. A.; BARBACONI, L. J.; PEREIRA, M. C. O que o IDEB não conta? Processos e resultados alcançados pela Educação Básica. Juiz de Fora: Editora UFJF, 2013.
COLODEL, D. L. e BRANDALISE, A. T. Tratamento da Informação nos Anos Iniciais do Ensino Fundamental: entre concepções e práticas. In: Anais do II Simpósio Nacional de Ensino de Ciência e Tecnologia, 07 a 09 de outubro de 2010.

CORRÊA, A. A. Saberes docentes e Educação Estatística: composições analíticas no Ensino Médio. Educ. Matem. Pesq., São Paulo, v. 14, n. 1, p. 6783, 2012.

COSTA, A.; NACARATO, A. M. A Estocástica na Formação do Professor de Matemática: percepções de professores e de formadores. Bolema, Rio Claro - SP, v. 24, n. 39, p. 367-386, ago. 2011.

COSTA, N. M. L.; POLONI, M. Y. Percepções de concluintes de Pedagogia sobre a formação inicial do professor para a docência de Matemática. Bolema, Rio Claro - SP, v. 26, n. 44, p. 1289-1314, dez. 2012.

CURY, H. N. Concepções e crenças dos professores de matemática: pesquisas realizadas e significados dos termos utilizados. Bolema, São Paulo: Unesp, v. 12, n. 13, p. 29-44, 1999.

ESTRADA, A.; BATANERO, C. Explaining teachers' attitudes towards statistics. In: Proceedings of the ICMI Study 18 Conference and IASE 2008 Round Table Conference. Joint ICMI/ IASE Study: Teaching Statistics in School Mathematics: Challenges for Teaching and Teacher Education. Monterrey: Mexico, 2008.

ESTRADA, A.; BAZÁN, J. L.; APARICIO, A. Un estudio comparativo de las actitudes hacia la estadística en profesores españoles y peruanos. UNION Revista Iberoamericana de Educación Matemática, Buenos Aires, n. 24, p. 45-66, dez. 2010.

FARIAS, A.; SOARES, J.; CÉSAR, C. Introdução à Estatística. Rio de Janeiro: Ed. LTC, 2003.

FERREIRO, E. Reflexões sobre alfabetização. 26 ed. São Paulo: Cortez Editora. 2011.

FRANKLIN, C. et al. Guidelines for assessment and instruction in statistics education (GAISE) Report: A Pre-K-12 Curriculum Framework. Alexandria, VA, March. 2005. Endorsed by the American Statistical Association August 2005. Disponivel em: <https:// www.amstat.org/education/gaise/GAISEPreK-12. htm>. Acesso em: 07 dez. 2016.

FREIRE, P. Pedagogia do Oprimido. Rio de Janeiro: Paz e Terra, 1974. 


\section{PERCEPÇÕES DE PROFESSORES DOS ANOS INICIAIS DO ENSINO FUNDAMENTAL EM RELAÇÃO \\ AO ENSINO DE ESTATíSTICA | Ailton Paulo de Oliveira Júnior; Márcia Lopes Vieira}

GAL, I. Adult's Statistical Literacy: Meanings, Components, Responsibilities - Appears. Internacional Statistical Review, v. 70, n. 1, p. 1-33, 2002.

GUIMARÃES, G. et al. A educação estatística na educação infantil e nos anos iniciais. Revista Zetetiké, Campinas (SP), v. 17, n. 32, dez. 2009.

HOUAISS, A.; VILLAR, M. S. Dicionário Houaiss de Língua Portuguesa. Rio de Janeiro: Objetiva, 2001.

HUFFMAN, D.; GOLDBERG, F.; MICHLIN, M. Using computers to create constructivist learning environments: Impact on pedagogy and achievement. Journal of Computers in Mathematics and Science Teaching, Waynesville, USA, v. 22, n. 2, p. 151-168, 2003.

INSTITUTO BRASILEIRO DE GEOGRAFIA E ESTATÍSTICA. Escola Nacional de Ciências Estatísticas - ENCE, 2015. Disponível em: <http://www. ence.ibge.gov.br/index.php/portal-graduacao/portalgrad-estatistica>. Acesso em: 12 set. 2016.

LEMOS, M. P. F.; FERREIRA, V. G. G. O estudo do tratamento da informação nos livros didáticos das séries iniciais do ensino fundamental. Ciência e Educação, Bauru, v. 12, n. 2, p. 171-184, 2006.

LOPES, C. A. E. A Educação Estatística no currículo de Matemática: um ensaio teórico. In: Reunião Anual da ANPED, 33., 2010. Anais... Caxambu (MG), 2010.

LOPES, C. A. E. et al. Os desafios para Educação Estatística no currículo de Matemática. In: LOPES, C. E.; COUTINHO, C.; ALMOULOUD, S. (Org.). Estudos e reflexões em Educação Estatística. Campinas: Mercado de Letras, 2010.

LOPES, C. A. E. Reflexões teórico-metodológicas para a Educação Estatística. In: LOPES, Celi E.; CURI, E. Pesquisas em Educação Matemática: um encontro entre a teoria e a prática. São Carlos/SP: Pedro \& João Editores, 2008, p. 67-86.

MACHADO, N. J. Educação: projetos e valores. São Paulo: Escrituras Editora, 2004.

MATSUSHITA, R. Y. O que é estatística? 2010. Disponível em: <http://vsites.unb.br/ie/est/ complementar/estatistica.htm>. Acesso em: 14 mar. 2014.

MENDES, A. M. Escuta e ressignificação do sofrimento: o uso de entrevista e análise categorial nas pesquisas em clínica do trabalho. In: Congresso de Psicologia Organizacional e do Trabalho, 2., 2006. Anais... Sociedade Brasileira de Psicologia Organizacional e do Trabalho (Org.), Brasília, DF, 2006. Disponível em: <http://www.sbpot.org.br/iicbpot/ anais.asp>. Acesso em: 15 nov. 2017.
MENDES, C. R. Alfabetização estatística, 2003. Disponível em: <http://revistaescola.abril.com.br/ matematica/pratica-pedagogica/alfabetizacao-estatistica-427480.shtml>. Acesso em: 02 fev. 2017.

MIGUEL, J. C. O ensino de Matemática na perspectiva de formação de conceitos: implicações teóricosmetodológicas, 2003. Disponível em: <http://www. inf.unioeste.br/ rogerio/Ensino-Matematica-Enfoque-Conceitos.pdf> Acesso em: 27 fev. 2017.

MILLER, J. The quest for the constructivist statistics classroom: viewing practice through constructivist theory. 2000. 307f. These (Ph.D. of Philosophy) Ohio State University, 2000. Disponível em: <http:// www.stat.auckland.ac.nz/ iase/publications/dissertations/00.Miller.Dissertation.pdf>. Acesso em: 15 nov. 2017.

OLIVEIRA JÚNIOR, A. P. de. et al. A percepção de professores dos anos iniciais do Ensino Fundamental sobre o ensino de estatística. In: Encontro Nacional de Educação Matemática, 11., 2013. Anais... Pontifícia Universidade Católica do Paraná, Curitiba - Paraná, 18 a 21 de julho de 2013.

ONUCHIC, L. R.; ALLEVATO, N. S. G. Ensinando Matemática na sala de aula através da Resolução de Problemas. Boletim GEPEM, Rio de Janeiro, v. 55, p. 1-19, 2009.

OSTROWER, F. Criatividade e Processos de Criação. 9 ed. Petrópolis: Vozes, 1993.

RAO, C. R. Statistics and truth: putting chance to work. 2. ed. Singapura: World Scientific, 1997.

ROCHA, I. A. A competência matemática no domínio da estatística no $1^{\circ}$ ciclo. Educação \& Matemática, Associação de Professores de Matemática, Portugal, n. 57, p. 29-30, mar./abr., 2000.

SANTOS, M. C. dos; ORTIGÃO, M. I. R.; AGUIAR, G. da S. Construção do currículo de matemática: como os professores dos anos iniciais compreendem o que deve ser ensinado? Bolema, Rio Claro, v. 28 , n. 49 , p. 638-661, 2014.

SILVA, C. B. Pensamento estatístico e raciocínio sobre variação: um estudo com professores de matemática. 2007. 354 f. Tese (Doutorado em Educação Matemática) - Pontifícia Universidade Católica, PUC -SP, São Paulo, 2007.

SOARES, G. A. Que saberes os professores dos anos iniciais acionam para o ensino da matemática. In: Conferência Interamericana de Educação Matemática - CIAEM-IACME, 13., 2011. Anais... Universidade Federal de Pernambuco, Recife, Brasil, 2011.

TRIOLA, M. F. Introdução à Estatística. Rio de Janeiro: LTC-Livros Técnicos e Científicos, 1998. 